DOI: http://dx.doi.org/10.5965/198431781642020001

\title{
COLETIVOS EM AÇÃO: PROCESSOS DE CRIAÇÃO E FORMAÇÃO NA INTERFACE ARTES, EDUCAÇÃO E SAÚDE
}

Acontecimentos recentes, como a nova pandemia COVID19, relembram-nos, de uma maneira brutal, que o mundo contemporâneo está cada vez mais marcado pela necessidade de transformação. Não de uma qualquer transformação que signifique um retrocesso civilizacional (aumento da desigualdade, perdas de direitos, liberdades e garantias), mas sim de uma transformação criativa. Uma transformação que nos ajude a lidar com os crescentes desafios apresentados pela multiplicidade e diversidade de um mundo que se globaliza, acelerado por conexões virtuais algorítmicas, alegadamente inteligentes, mas desprovidas de corpo e de consciência.

Para afirmar nossa existência coletiva neste planeta, torna-se indispensável conceber práticas e pensamentos inventivos em rede, carregados de sentidos, e neste campo, as artes - na interface com outros campos de conhecimento -, têm ocupado um lugar fundamental. A contribuição que aqui apresentamos inscreve-se nesta linha de pensamento criativo e colaborativo, descrevendo exemplos de projetos que, ajudando a unificar corpos e mentes, ousaram abrir caminho para ações coletivas transformadoras, no melhor sentido da palavra.

Partindo desse pressuposto, as pesquisadoras e o pesquisador proponentes deste dossiê - duas brasileiras e um português - já conectados com outros pares de diferentes estados do Brasil e de outros países, e que vem atuando em suas práticas e na produção de conhecimento em torno de temáticas comuns, resolveram se reunir e conceber esta proposta que, com alegria, aqui apresentamos.

Em meio ao processo deste dossiê fomos surpreendidos pelo evento da pandemia e seus efeitos em nossos corpos e vidas e que nos ofereceram a 
possibilidade de refletir sobre o sentido desta produção composta por experiências de caráter sensível, coletivo e presencial.

Citamos como marcas importantes deste processo: o esforço em tornar as etapas avaliativas em momentos de interlocução com vista a um maior afinamento dos textos; a flexibilização de prazos para os autores e autoras entendendo a pandemia como um evento determinante que alterou os nossos modos de pensar e organizar os cotidianos, influenciando os modos de escrever e produzir conhecimento; uma atenção às singularidades e ao diálogo permanente e atento com cada autor/autora ao longo de todo o processo de feitura do dossiê.

Gostaríamos de afirmar que todas as etapas do processo desta publicação, afinadas com o caráter colaborativo também presente em todas as experiências aqui relatadas, possibilitaram o prosseguimento e finalização deste trabalho.

O dossiê é composto por 11 artigos norteados por práticas artísticas realizadas em projetos coletivos com ênfase territorial e/ou proposições artístico-pedagógicas realizadas no espaço acadêmico.

Temos como objetivo dar visibilidade (ainda mais!) a essas experiências realizadas no encontro entre-corpos, afirmando a sua força, delicadeza e fundamentalidade, provocando uma discussão sobre algumas de suas ressonâncias.

Em uma abordagem multidimensional destacam-se as temáticas: processos de criação; processos de ensino-aprendizagem; coletivo, diversidade e a produção do comum; corporeidades e territórios. Tais temas que se efetuam em práticas singulares realizadas com pessoas que muitas vezes se encontram em condições de vulnerabilidade - social, econômica, física, psíquica, emocional, portanto, existencial - permitem uma recolocação de problemas no campo da interface educação, artes e saúde.

Nos interessa assim, colocar essas experiências como locus de investigação de chaves teóricas, metodológicas e epistemológicas nos diálogos entre os saberes, tendo em vista a urgência de fazer-pensar outros modos de viver e conviver na diversidade. 
Durante a elaboração e ao finalizarmos o dossiê, foi possível reconhecer uma ampliação da rede de pesquisadores, artistas, profissionais de diferentes campos de conhecimento que com suas experiências, expressam o cultivo atento às temáticas para nós tão potentes, desafiadoras e vivas, corporificadas por meio de ações coletivas regadas pelas artes e afetividade.

Tal como aconteceu conosco, organizadores, esperamos que, com este dossiê, os leitores, sejam inspirados e inspiradas por estas experiências e discussões, potenciando outros encontros, conexões virtuais e presenciais, novas pesquisas e novos projetos/sonhos na interface artes, educação e saúde e seus devires.

Apresentaremos a seguir aspectos principais de todos os artigos como um convite ao encontro e ao mergulho em suas águas.

Iniciamos o dossiê com o artigo "Dramaturgias da Solidariedade" de Tania Alice que nos apresenta a noção de dramaturgia no campo da performance, apontando a perda de sua primazia textual concedida pelo eurocentrismo, para se abrir a manifestações somáticas da ordem do acontecimento. Para a autora, o novo espectador das dramaturgias contemporâneas assume um papel fundamental na composição, que se torna coletiva, podendo, na performance, ir até a alteração do programa performativo inicialmente proposto pela/o artista. Escolhendo a forma da carta/diário, registro de sua pesquisa cartográfica em torno de um projeto europeu participativo de performance, a autora pensa uma "Dramaturgia da Solidariedade", que poderia inscrever-se no campo mais amplo de "Poéticas do Cuidado", abrindo espaço para novas possibilidades do fazer artístico.

No segundo artigo "Figuras emergentes entre as artes e a clínica - exercícios iniciais para pensar performances do vivo na Cia Teatral Ueinzz", de Erika Alvarez Inforsato, são apresentadas as chamadas "figuras emergentes", marcadas pela loucura, pela deficiência, e outras linhas de risco e desertificação. Estas figuras proliferam em número e em potência de diferenciação, no contágio com alguma arte, presente em tentativas da Cia. Teatral Ueinzz, que propõe produzir, há 22 anos, experiências que se efetuam na zona fronteiriça entre as artes e a clínica na cidade 
de São Paulo. A autora sustenta que, neste coletivo, se opera uma ética de deslocamentos e embaralhamentos dos códigos hegemônicos que fixam modos de existir num funcionamento excludente, apontando a exigência de uma clínica imersa em seu paradoxo que estes escritos buscam problematizar.

$\mathrm{Na}$ sequência encontramos o artigo de "Desconstrução da bipedia compulsória na Dança", partindo da concepção de que todo corpo é corpomídia potente para construir discursos poéticos a partir das experiências que o constituem, Carlos Eduardo Oliveira do Carmo e Fátima Campos Daltro de Castro investigam a construção da dança em múltiplos corpos evidenciando o corpo como um processo vivo, cognitivo e auto-organizador. Apesar de todo o avanço no campo da dança, o corpo dançante com deficiência ainda é excluído pela soberania do pensamento bípede que o entende como incapaz e não produtivo. Nesta importante reflexão, a dança é um recorte que revela, em si, um comportamento social predominante. Aposta-se então que a construção de conhecimento da dança sobre o corpo, em sua interseccionalidade com outras áreas, seja fundamental no enfrentamento do pensamento hegemônico que reitera padrões funcionais e corporais excludentes em relação às pessoas com deficiência.

O quarto artigo "Dança, deficiência, educação acessível e formação de professores: experiências e teorizações em percurso", de Ana Maria Rodriguez Costas apresenta e reflete sobre suas experiências em disciplinas dedicadas à dança e seu ensino, em uma perspectiva inclusiva, em cursos de graduação na área. Em um percurso de duas décadas a autora destaca suas percepções sobre as mudanças no cenário político-educacional, nos contextos educacionais e artísticos reverberando na transformação de conceitos, temáticas de estudo, metodologias e proposições que desenvolve com suas alunas e alunos. No relato das experiências é possível identificar alguns fundamentos norteadores para a concepção de currículos, a potencialidade da prática como componente curricular, a relevância das colaborações entre universidade e sociedade e, as composições e encontros na diversidade no espaço da própria sala de aula. O texto nos convida a pensar que, apesar de avanços significativos, os estudos sobre dança, deficiência e educação acessível seguem 
sendo fundamentais, e, portanto, exigem espaços-tempos para experiências e reflexão crítica nos cursos de formação de professores de dança.

As autoras canadianas Albane Buriel, Sylvie Morais e Monique Loquet no artigo “A 'biografia artística' com jovens deslocados em acampamentos no Iraque: presença como indicador de resiliência", fazem a descrição de uma intervenção artística inclusiva, levada a cabo com crianças afetadas pelo conflito da guerra do Iraque, com o intuito de aumentar a sua resiliência e empoderamento. Os atuais conflitos armados no mundo - e, em particular, aqueles ligados ao Sistema de Estado Islâmico (ISIS) -, constituem um grande obstáculo para a estabilidade das referências sociais e para uma sociedade livre dos sintomas da Guerra. A implementação deste dispositivo de atividades de "biografia artística", convida ao desenvolvimento de investigação nesta área de intervenção, assim como alerta para as possibilidades e limitações da implementação de projetos de resposta artística em emergências humanitárias.

No sexto artigo "Um olhar sobre o impacto da experiência teatral no exercício da alteridade e no processo de socialização de crianças em contextos educacionais", as autoras Célida Mendonça e Isabel Bezelga, apresentam uma série de reflexões resultantes de experiências formativas de base teatral. A primeira trata-se de um recorte da experiência de ensino vivenciada com os alunos do curso de Licenciatura em Educação Básica da Universidade de Évora (Portugal), na disciplina Oficina de Integração das Expressões; a segunda é dedicada a questões suscitadas pelo fazer teatral desenvolvido com crianças, no contexto de educação básica $1^{\circ}$ ciclo na Escola da Cruz da Picada. As múltiplas possibilidades oferecidas pelas materialidades em jogo nos dois contextos, abrem perspectivas aos participantes pensando e fazendo, para serem inventivos e sensíveis. Como o processo de aprendizagem passa pelo seu corpo e corpo do outro, permite vivenciar novas formas de comunidade, concebendo de modo mais amplo a alteridade. Os resultados obtidos voltam-se para o aperfeiçoamento da formação de docentes e pesquisadores da pedagogia do teatro no contexto brasileiro e português construindo novas colaborações. 
Em seguida, Luciana Caliman, Janaína Mariano César e Virgínia Kastrup no artigo "Práticas de cuidado e cultivo da atenção com crianças" apresentam um estudo que analisa uma experiência na qual crianças diagnosticadas com Transtorno de Déficit de Atenção e Hiperatividade (TDAH) e outros problemas relacionais, usuárias de um Centro de Atenção Psicossocial Infantojuvenil (CAPSi), participam de uma oficina de leitura de literatura. Realizada como uma pesquisa-intervenção baseada no método da cartografia, a Oficina da Palavra é ofertada como uma alternativa ao uso da medicação como tratamento principal, e constitui-se como dispositivo grupal e participativo, simultaneamente, de leitura e de cuidado. A proposição de um dispositivo grupal de cuidado acentua a dimensão conjunta da atenção e a importância da construção de ecossistemas atencionais nos quais a atenção a si e aos outros possam ser cultivadas. As autoras concluem que a partir de uma perspectiva ecológica, o cuidado dos problemas atencionais emerge como um ato de cultivo de correspondência e atenção conjunta concentrada e aberta, implicando na construção de ecossistemas atencionais favoráveis.

No oitavo artigo, as pesquisadoras Flavia Liberman, Marina Guzzo e Elizabeth de Araújo Lima, nos apresentam o artigo "Pequenos deslocamentos: uma experiência de criação e formação com mulheres de um território vulnerável na cidade de Santos". As autoras buscam problematizar a ideia de pequenos deslocamentos, que são experimentados no contexto de práticas de formação, para compor outros modos de atuar em saúde - compreendida como possibilidade de promover acesso à experiência estética e à vida em sua potência expressiva e criativa. Para tanto apresentam alguns aspectos de um projeto artístico/ formativo que envolve mulheres que apresentam diferentes desafios de ordem física, emocional e social e os estudantes de uma universidade pública. Ancoradas em uma perspectiva micropolítica, as pesquisadoras consideram os pequenos deslocamentos como marcas microscópicas, movimentos menores dentro das experiências em sua potência de ativar e incidir em processos de subjetivação e produção de outras sensibilidades, apostando nas pequenas interferências como modo de produzir uma 
formação inventiva para os alunos e o aumento de potência individual e coletiva que se efetua na interface corpo, arte, saúde e educação.

No artigo "Exploração táctil da Belgrado urbana - unindo olhares femininos através do projeto wa(o)ndering women" das autoras sérvias Maja Maksimović, Jelena Joksimović e Mirjana Utvić, descreve um estudo que procura descobrir elementos da aprendizagem, praticando o direito à cidade através da incorporação e re-articulação da identidade da flâneuse. Uma vez que a deambulação implica um desvio das ruas principais, o processo de aprendizagem torna-se marcado pela imprevisibilidade e pelo serpentear na cidade, em deambulações reflexivas e performativas. Nesta investigação urbana as autoras exploram perspectivas emergentes da cidade, a forma como estas estão conectadas com lugares específicos e a maneira como formam o nosso devir, tendo em mente uma divisão da vida urbana de acordo com o género. A investigação envolve reminiscências das deambulações de mulheres em Belgrado que as autoras quiseram recriar e documentar, através do mapeamento das suas próprias experiências.

No penúltimo artigo intitulado "Jogo da amarelinha: o método-livro e os modos de dizer, sentir e olhar uma cidade" de Laura Barcellos Pujol de Souza e Luciano Bedin é apresentada uma pesquisa-montagem feita a partir de rastros, escritos urbanos, achados no chão encontrados na cidade de Porto Alegre (RS) entre 2017 e 2018. Estes rastros e os fragmentos de escrita produzidos a partir do encontro dos pesquisadores com os materiais, compõem o que os autores chamam de método-livro, tendo como intercessor $O$ jogo da amarelinha (Rayuela) de Julio Cortázar. As narrativas cartográficas dos deslocamentos inspiram modos de dizer, sentir e olhar as múltiplas paisagens urbanas, que se escondem e também se revelam no encontro com uma cidade, em um movimento operado pelo que chama de escreverCOM. $\mathrm{O}$ artigo finaliza ensaisticamente com a escrita de um manifesto pelo método-livro, onde são sinalizadas algumas premissas a quem por este também se interesse.

Finalizando o Dossiê temos o artigo "Corpos em trânsito", um delicado e potente relato-reflexão sobre uma experiência de dança desenvolvida por Anamaria 
Fernandes Viana junto a um grupo de mulheres acolhidas no Setor Psicológico da Penitenciária de Mulheres da cidade de Rennes (França) e algumas profissionais da saúde daquele espaço. $O$ texto é alimentado por reflexões e anotações colhidas de um caderno de bordo que acompanhou a autora durante as aulas ministradas para esse grupo no ano de 2018. Sua leitura nos permite acompanhar a construção de um espaço comum moldado por esses corpos em trânsito. De forma cronológica, propõe-se ao leitor o compartilhamento desta densa experiência em que hesitações, descobertas, surpresas, questionamentos, adversidades e tensões são reveladas no cotidiano dos encontros de trabalho e dentro da própria unidade prisional. Aos poucos, vamos contemplando a transformação daquelas mulheres e nos tornamos testemunhas da reafirmação da autora quanto à potência das práticas artísticas em contextos sociais inabituais.

Ana Maria Rodriguez Costas (Ana Terra) Universidade Estadual de Campinas - UNICAMP anaterra@unicamp.br | ORCID | LATTES

Flavia Liberman Universidade Federal de São Paulo - UNIFESP f.liberman@unifesp.br | ORCID | LATTES

José Eduardo Silva Centro de Estudos Humanísticos da Universidade do Minho - CEHUM jeduardosilva@ilch.uminho.pt | ORCID | Ciência ID

Editores do dossiê "Coletivos em ação: processos de criação e formação na interface artes, educação e saúde" 